\title{
ECOSYSTEM SERVICES FROM AGRICULTURE AS KEY FACTOR OF TERRITORIAL COMPETITIVENESS
}

\author{
M. Peneva* \\ Department of Natural and Resources Economics, University of National and World Economy, \\ Sofia, Bulgaria
}

\begin{abstract}
Purpose of the research: Agriculture is a dominant form of land management, delivering products (food, fodder and non-food) to meet human needs. The production process also has various externalities for its surroundings. Therefore, the notion that agriculture does not only provide/produce commodity outputs but also performs additional functions (ecosystem services) and creates non-commodity outputs (public goods), necessitates the analyses of the ecosystem services provided by agricultural activities in the territorial context. The aim of the paper is to present and assess the causal connections between ecosystem services provided by agricultural production and their contribution to the territorial competitiveness. Methods of the research: The analysis is based on the example of the case study region as a comparative analysis and synthesis of scientific literature and the methods of induction and deduction were used to investigate the theoretical aspect and characteristics of ecosystem services provision and territorial competitiveness. Later, mathematical modelling is applied. Results and conclusion: It was found that different ecosystem services and non-commodity outputs have a positive influence on territorial competitiveness as the strongest impact is from the agricultural land resulting from provisioning ecosystem services (food, water quality regulation, soil formation, recreational benefits etc.).
\end{abstract}

Key words: Public Goods, Agriculture, Territorial Competitiveness

\section{INTRODUCTION}

Agriculture is a dominant form of land management. In essence, its social value consists of the products it creates to meet human needs. Food is a vital necessity but besides producing traditional commodities (e.g. food and fiber), agricultural sector also supplies several other goods to society such as landscape, environment, biodiversity, food security. Agriculture in Europe is not only responsible for the supply of food and raw materials but occupies about $40 \%$ of the land area. Consequently it has a powerful influence on the state of the rural environment and the opportunities for its enjoyment.

Last hundred years the production process and farming systems all over the world have been changed. These changes (intensification, mechanisations, fertilisation etc.) were economically driven but lead to a range of

\footnotetext{
*Correspondence to: Mariya Peneva, Department of Natural and Resources Economics, University of National and World Economy, 1700 Sofia, Studentski grad, Bulgaria, Tel.: +359281 95 315,E-mail: peneva_mm@yahoo.co.uk
}

various negative externalities affecting the surroundings: environment, biodiversity and landscape in rural areas and behind, and their quality depends on the ways in which the land is managed. And it has been discovered that these externalities could be positive such as public goods and their use effects into economic activities, have a special role in rural areas development as a whole. Therefore, the notion that agriculture does not only provide/produce commodity outputs but also performs additional functions (ecosystem services) and creates non-commodity outputs (positive/negative public goods) necessitates the analyses of the ecosystem services provided by agricultural activities in the territorial context. Moreover, the agriculture has traditionally been the main socio-economic activity in rural areas and land-based activities remain vital to its image and appearance. The agriculture is also important source of employment in rural Europe and provides income to a large proportion of its population. Accordingly, it is of scientific interest to analyse how the ecosystem services provision affects territorial competitiveness due to the recently continuously growing interest in the 
problems of complex territorial governance and its dimensions to ensure better competitiveness.

The aim of the paper is to present and assess the causal connections between ecosystem services provided by agricultural production and their contribution to the territorial competitiveness based on a case study research.

Provision of public goods from agriculture (ecosystem services) and territorial competitiveness are broadly discussed concepts. The provision of public goods is recognized also as one of the key topics for the future of agriculture and rural policy in European Union (1-2) since the Common Agricultural Policy has been considered as a major driver of land use and farming practices changes in Europe. The competitiveness and its evaluation play also a significant role in the European Union and all over the world as the interest is expressed at three levels: firms (micro, business), nations (macro, industry) and regions (mezzo, territory). The most discussed among scientist is the third one as the definition, conceptualisation and the measurement of territorial competitiveness is still ongoing. Therefore, in Section 3 are presented reviews of the ecosystem services and territorial competitiveness concepts. In addition to this part the paper is structured as follows. Section one is Introduction. Section 2 continues with the materials and methods used in the paper as well as the short introduction of the case study area is outlined. Finally, section 4 presents discussion of the results and drown conclusions.

\section{MATERIALS AND METHODS}

The paper is based on the territory-based approach and focuses attention on the functions provided by the agriculture to the whole territory. The analysis is based on the example of the case study region as a comparative analysis and synthesis of scientific literature and the methods of induction and deduction were used to investigate the theoretical aspect and characteristics of ecosystem services provision and territorial competitiveness. Later, Data Envelopment Analysis (DEA) is applied.

DEA analysis is used to differentiate the relative productivity and territorial (regional) competitiveness. It is mathematical programming technique which allows us to measure the relative efficiency of a decision making unit (in regional/territorial analysis usually these are the economic sectors) relative to other units. In DEA the inputs are measured by the labour (cost or number of workers), new investments and government expenditures which resulted in changes in the regional gross domestic product and local government's revenues. In general it measure and analyse the differentiation between relative productivity (efficiency) and regional competitiveness of economic sector between and within the regions and in an inter temporal context provides evaluation of the efficiency of local regions across a range of output and input measures benchmarked against national performance and that of other regions.

DEA is a relatively new data-oriented approach for assessing efficiency, modelling operational processes and evaluating the performance converting multiple inputs into multiple outputs. DEA is thus a multicriteria decision-making method for evaluating the effectiveness, efficiency and productivity of homogeneous groups (i.e. sectorial performants). It has been initially developed by Charnes in response to the need for satisfactory procedures to assess the relative efficiencies of multi-input and multi-output production units (20). It is recognized that due to its low assumption requirements, DEA has also opened up possibilities for use in cases that have been resistant to other approaches because of the complex nature of the relations between multiple inputs and outputs. Melecký concludes DEA is a convenient method for comparing national or regional efficiency as an assumption for the performance of a territory, because it evaluates not only one factor, but also a set of different factors that determine the degree of economic development. For this purpose, the DEA method can identify the competitive position of each country and region (21). The method allows to measure the level of efficiency of the units, and to identify benchmarks against which inefficient units can be compared. In general, the process is presented as benefit/cost ratio as the basis for the standard ratio of productivity:

$$
\sum_{r} \bar{u}_{r} y_{r j} / \sum_{i} \bar{v}_{i} x_{i j}
$$

Where the efficiency of each decision making unit is presented as the ratio of weighted outputs to weighted inputs and from a set of units $\mathrm{j}(\mathrm{j}=1, \ldots, n)$ uses multiple inputs Xij $(\mathrm{i}=$ $1, \ldots, \mathrm{m})$ and generates multiple outputs $\mathrm{Yrj}(\mathrm{r}=$ $1, \ldots, \mathrm{s}$ ) and the prices (multipliers) Ur and $\mathrm{Vi}$ are associated with the inputs $i$ and outputs $r$, respectively. Later, this can be converted to the linear programming model and the similarity can be interpreted as closeness between the 
inputs and outputs of the assessed unit and the proposed targets.

\section{THE CONCEPTS AND THE CASE STUDY}

\section{Ecosystem Service and Public Goods from Agriculture}

The environmentally-damaging aspects of modern farming and forestry practice were first identified and described as 'negative externalities' - i.e. practices which led to negative environmental 'side-effects' from modern agriculture and forestry production, largely external to the considerations of those engaged in production. However as Dwyer et al. stated, in analysing these processes it became apparent that agriculture could be generators of both negative and positive externalities for the environment - either causing environmental or socio-cultural damage, or conversely, helping to maintain environmental or social assets which had 'coevolved' with often long-established 'traditional' production systems. Thus the relationship between primary food, fuel and fibre production and environmental or social assets and attributes could vary between conflict and antagonism at one extreme, to synergy at the other, depending upon local circumstances. (3)

Most of these outputs convey the characteristics of public goods. And agriculture in Europe is defined as essential for the provision of a whole range of public goods due to the fact that many aspects of the countryside most valued by visitors and which they expect rural areas to provide, are public goods (e.g. birds, wildflowers, high quality air, soil and water, scenic landscapes, etc.). In addition it is proved agriculture help to provide stable climate and improving the resilience of the land to natural disasters and its most essential role is in delivering public goods such as food security, economic vitality, social and cultural prosperity of rural life and the wider rural territory. (4)

The term 'public good' has been developed in the economic literature to describe and analyse a range of goods and services which are not delivered through the market and as the interplay of supply and demand, such of the above mentioned. A public good is described as a resource that is non-excludable, nonrivalrous, and open to all in its consumption and according to the economic theory there is a shortfall in provision it through the markets, because producers have insufficient incentive to provide them and consumers have insufficient incentive to pay for them.
According to ERDN report in parallel to the development of the concept of public good in economics, an approach has been developed from ecological science to describe the same multiple dimensions describing the depends of present societies upon certain functions of the ecological systems within which they are embedded. Thus the field of research of ecosystem services has evolved. Currently, the initial ecological understanding used to raise awareness about human dependence upon ecological systems includes more and more economic elements aimed at influencing public policy and regulations. (4) So, ecosystem services have emerged as a concept used to convey the importance of, and value of, natural systems to society and the economy (6-7) and to describe the functional roles played by components of ecological systems, which need to be recognized and valued (in more or less concrete ways) in decision-making and resource allocation (3). This approach allows identifying any interrelationship between society and its economic activities with the natural resources having in mind that without the services provided by the nature the existence and prosperity of the society and economy would not be possible.

Recent research work within the scientific project found out that the lack of market prices for many public good-type ecosystem services may affect general awareness and valorisation. From the territorial competitiveness assessment perspective it is important their conclusion that despite many ecosystem services are often considered important at local level because of heritage or social identity preservation, their potential to support wider regional social or economic objectives is not recognised unless the ecosystem services have some direct market value (5) or compensations paid within the policy framework. Thus, ecosystem services concept is currently anchored into different public policies, applying the classification given in the Millennium Ecosystem Assessment and differentiating them as provisioning, regulating, supporting, and cultural services. Namely, in the paper ecosystem services is the term used to describe the common understanding of public goods provisioning by the nature as part of the agricultural production process.

In regard to the agriculture and agricultural production, farming systems are both providers and consumers of ecosystem services. Power (8) describes this as a process in which "humans value these systems for their provisioning services, and these highly 
managed ecosystems are designed to provide food, forage, fibre, bioenergy and pharmaceuticals. In turn, agroecosystems depend strongly on a suite of ecosystem services provided by natural, unmanaged ecosystems." Farming activities are critical for ecosystem services provision and different farming and management systems recognize and support these outcomes differently, depending on the farmers' actions and understandings, but also taking into consideration the current market situation, policy measures and requirements, institutional developments, general public behavioural, societal believes and culture and other factors. Having in mind that awareness and demand for public goods also is often determined by regional specificities, Kretsch et al. (5) stated that governance strategies (local, regional, territorial) with regard to public good-type service provision have to be specific to local conditions and to local social, economic, and cultural contexts.

\section{Territorial Competitiveness}

In the literature there is not one and only definition of competitiveness taking into account different perspectives and levels of its application as well as the question how to measure it. The concept of competitiveness has quickly spread to the regional, urban and local level, but the idea of territorial competitiveness still remains controversial depending on the context of the analysis and the level of the territory (nations, regions, cities, rural areas). Generally, competitiveness is defined by the productivity of the object and the meaning of the term "competitiveness" is defined by the European Union as "to be able to withstand market competition" (9). Compared to that and having in mind specificities of the territories their competitiveness should be linked with their attractiveness described by the investment level, human resources quality, natural worth, infrastructure and technologies developments/implementation etc. And current economic developments are determined by the processes of shifting of production activities to places with better conditions. In this regard is defined the regional competitiveness of the European Union found in the last edition of the Regional Competitiveness Index report: "Regional competitiveness is the ability of a region to offer an attractive and sustainable environment for firms and residents to live and work." (10) Following the two definitions applied at European Union level can conclude that productivity and employment are key elements of the territorial competitiveness interconnected with the living standard. It is clear that the territorial competitiveness is far beyond the productivity and includes also social and sustainability aspects. In this sense the ability of institutions and actors for common actions are important as well as the natural and cultural heritage preservation in order to complement the dimensions of territorial competitiveness in long term perspective.

Moreover, Porter's work on competitiveness evolved and he defines that globally, regions became the drivers of the economy and one of the most striking features of regional economies is the presence of geographic concentrations. (11) In global economy, regions are becoming the drivers of economy. Thus, the governmental interest in the regional foundations of national competitiveness has grown and provoked development of new forms of regionally based policy interventions towards improvement of the territorial competitiveness (12) as general. Inevitably it requires shift of the decision-making and coordination of the activities. In the paper the term territorial competitiveness is used namely in the ability of the territory to create a competitive position and to maintain it in the internal and external markets. This definition assumes that territorial competitiveness is a reinforcing process, where current factors of the competitiveness create the future ones. (13) But the factors determining territorial (regional) competitiveness can be defined at different level depending on their characteristics and involve: quality and quantity of primary production factors: labour, capital and land; quality of place and environment; investment climate and infrastructure and accessibility; institutions, internationalisation and technology etc.

Evaluation of the competitiveness and analysing the driving factors are complex issues constantly in the forefront of economic sciences. Staníčková et al. and Zhu consider the decomposition of aggregate macroeconomic indicators as the most common approach of evaluation used at the regional level, as well as comprehensive (mostly descriptive) analysis aimed at identifying the key factors of regional development, productivity and economic growth. (14-15) Other approaches present macro econometric modelling with creation of an econometric panel data regression model developed by Baltagi et al., Garrat et al. and Nevima et al. (16-18) and/or DEA method measuring regional efficiency and 
subsequently measuring regional competitive potential (19-20).

\section{Case Study Region}

The case study area is part of the research activities within the project BIOGEA (BiodivERsA network project; see acknowledgements) and it is focused on the Plovdiv-Pazardjik region (part of the South Central region - NUTS 2/3 level). The territory of interest has a varied relief with mountainous and semi-mountainous areas, river valleys and lowlands. The climate, with well-defined four seasons, is of a Mediterranean type, with the exception of the mountainous parts. It is a well-developed agricultural region, favoured by nature in the country and belongs to the nature vulnerable zones (existence of protected area and NATURA 2000 designated zones). The soils are among the most fertile in Bulgaria, suitable for growing of cereals, oleaginous, industrial crops, fruits, vegetables and vineyards. On an average the agricultural land in the region amounts to $48 \%$ of the total land. Livestock farming (sheep and cattle) is well developed also due to the presence of large areas of grasslands.

Agricultural activities within the territory simultaneously provoke environmental challenges (industrialisation and intensification to monocultures, plough of grass land to plant cereals; decrease in pastured livestock and unsustainable grazing; abandonment and land conversion; non-nature friendly agricultural practices (burnings of stubbles and pastures, usage of pesticides); abandonment of the traditional agricultural practices (boundary strips, woodland and shrub vegetation) and generates ecosystem services presented in Table 1. In the paper the TEEB data base is used as a benchmarking for assessment of the economic value of the identified ecosystem services in the region. (22-23)

The TEEB data base use the main ecosystem services classification proposed by the Millennium Ecosystem Assessment and subdivided services to detailed products/services to be measured/assessed economically. For the chosen case study territory are identified the following functions with respective subservices of importance: provisioning (food and raw materials: food, fodder, fuel wood; genepool: biodiversity protection, animal genetic resources; nursery: nursery service), regulating (climate: c-sequestration; waste: water purification), supporting (erosion: erosion prevention; soil fertility: soil formation, nutrient cycling), and cultural (cultural service: cultural values; recreation: recreation, tourism). Additionally, each one of the identified subservice in TEEB is considered depending on the geographical location of the territory, e.g. country/region/continent having in mind the internationally recognized territories, the level of protection of the respective area/landscape and its/their 'scale'/size which allowed us to identify territories with same geographical location which helped us to identify precisely the one relevant to the territory of interest. Later, different evaluation methods (direct market pricing, benefit transfer, avoided cost or standardized unit) are applied to calculate the respective economic value usually in value type annual per hectare values. The data base accurately specifies the year of values calculation which allows us to recalculate them to current values taking into consideration the official exchange rate and the inflation processes if any.

Thus in the Table $\mathbf{1}$ are presented standardised estimation of the monetary values of ecosystem services provided by the agricultural activities in the Plovdiv-Pazardjik region which later will be used to recalculate prices associated with the inputs and outputs (both not taken into consideration in the economic performance indicators for the respective decision making unit, sector) of the decision making units for the sake of DEA analysis.

\section{RESULTS AND DISCUSSION}

The above defined ecosystem services correspond to the used definition in the paper. It is obvious they are territory-based as consequences of agricultural activities and are interlinked with the other up and down stream businesses, even with the non-agricultural sectors. Moreover, it is clear that their effects go beyond the farm (micro) level and support improvements in the territory competitive position and better its competitiveness in internal and external markets. It means that the estimated ecosystem services contribute to the local economy, especially the once that are non-commodity outputs which real value is evaluated only through the share in the local area. Besides the expert assessment and the choice of the relevant ecosystem services from the whole TEEB recognize regional differences in the societal demand for the functions of agriculture: some of the local areas consider more important production, others recreation or ecology, calculating different local effects. 
Table 1. Estimation of the monetary values of ecosystem services provided by the agricultural activities in the case study region

\begin{tabular}{|c|c|c|c|}
\hline \multicolumn{2}{|r|}{ Ecosystem } & \multirow{2}{*}{ Value } & \multirow{2}{*}{ Unit } \\
\hline Service & Subservice & & \\
\hline Food & Food & 1915,68 & $\mathrm{BGN} / \mathrm{ha} / \mathrm{yr}$ \\
\hline \multirow[t]{2}{*}{ Raw materials } & Fuel wood and charcoal & 370,21 & BGN/ha/yr \\
\hline & Fodder & 116,52 & BGN/ha/yr \\
\hline \multirow[t]{2}{*}{ Genepool } & Biodiversity protection & 732,38 & $\mathrm{BGN} / \mathrm{ha} / \mathrm{yr}$ \\
\hline & Animal genetic resources & 1004,73 & BGN/ha/yr \\
\hline Nursery & Nursery service & 4473,85 & BGN/ha/yr \\
\hline \multirow[t]{2}{*}{ Recreation } & Recreation & 94,31 & BGN/yr \\
\hline & Tourism & 279,98 & $\mathrm{BGN} / \mathrm{yr}$ \\
\hline Cultural service & Cultural values & 655,75 & $\mathrm{BGN} / \mathrm{yr}$ \\
\hline Waste & Water purification & 633,65 & BGN/ha/yr \\
\hline Climate & C-sequestration & 48739,32 & $\mathrm{BGN} / \mathrm{yr}$ \\
\hline Erosion & Erosion prevention & 1053,77 & BGN/ha/yr \\
\hline \multirow[t]{2}{*}{ Soil fertility } & Soil formation & 923,89 & BGN/ha/yr \\
\hline & Nutrient cycling & 4865,10 & $\mathrm{BGN} / \mathrm{ha} / \mathrm{yr}$ \\
\hline
\end{tabular}

Source: TEEB Valuation Database, http://www.teebweb.org/, own calculations

Provisioning of food and raw materials remain major contributor and is crucial for the development of other sectors as tourism, processing industry and trade. On the other hand regulating functions benefit all economic sectors and the residents through improved climate conditions and water purification (even decrease the production costs in some cases). The supporting functions are vital for increasing productiveness and resilience of the productions, especially in agriculture and also influence the level of production costs. Cultural services benefit tourism and trade industries, increase self-satisfaction of the locals due to better image of the territory and its attractiveness. They also support recreation and improvements of tourists and local citizens' health.

Jointness of the agricultural production and ecosystem services (especially for diversification and creation of small and medium enterprises in other sectors) is very important to be analysed because the multiplier effects result in the development of the offfarming activities and better conditions for both businesses and residents contributing to the employment possibilities within the territory. It is obvious that this integration is happening at farm level and facilitates the shift of the non-marketed outputs into marketed which improves the condition of the territory and expands its competitive position. The field work in the case study area showed that this

process is running differently in the different parts of the territory which depends on the technical infrastructure and knowledge of the farmers and social developments between farmers, institutions and society. It has been proved that farmers' decision to organize and modify the production practices, to conserve and respect nature requirements and features in order to support and optimize ecosystem services provision depends on the their own (farm) costs and benefits of these actions. Hence, the benefits from ecosystem services are determined by their quantity and level of preservation, but also by their diversity across the territory.

Based on the calculations by DEA analysis, can state that that the case study region has the most significant contribution to economic performance of the territory (considered as the most competitive regions) and thus to the positioneffect of the respective NUTS 2 region and the overall competitiveness of the country. Despite of the increase into the economic performance of the areas designated for agricultural production adding to the economic values the once of the ecosystem services, the regions designated as economically powerful (main cities and surrounded territories) still achieve better results. The latter are 'efficient' which in DEA analysis results in efficiency index equal to one and serve as a benchmarking for the rest.

\section{CONCLUSIONS}

It is important ecosystem services, their analysis and valuation to be introduced and integrated into the territorial context in order to encompass the full range of functions/services/commodities provided within the process of agricultural production. Present study found out that different ecosystem services and non-commodity outputs from the agricultural production have a positive influence on territorial competitiveness as the 
strongest impact is from the agricultural land resulting from provisioning ecosystem services (food, raw materials, water quality regulation, soil formation, recreational benefits and tourism, etc.).

Acknowledgments: This study is performed in the framework of project BIOGEA: "Testing BIOdiversity Gain of European Agriculture with CAP greening (BiodivERsA3-2015-180)", implemented in the 2016-2019 period and funded by the Bulgarian National Science Fund under the contract $\mathrm{N}$ Д002/2.

\section{REFERENCES}

1. Beaufoy, G., and Marsden, K.K., CAP reform 2013 last chance to stop the decline of Europe's High Nature Value farming. Available online: http://www.efncp.org/download/policy-capreform-2013.pdf. 2011.

2. Nikolov, D., Radev T., and Borisov P., Landscape as a driver for competitiveness of Pazarjik district in Bulgaria. 2nd AIEAA Conference - Between Crisis and Development: which Role for the BioEconomy Parma, 6-7 June 2013. 2013.

3. Dwyer, J., Christopher, J., Berriet-Solliec, M., Gael-Lataste, F., Pham, H-V., Affleck, M., Courtney, P., Déprès C., Public Goods and Ecosystem Services from Agriculture and Forestry - a conceptual approach. Project Report. Pegasus - Institute for European Environmental Policy. Available online: http://pegasus.ieep.eu/. 2015.

4. ERDN., Public goods and public intervention in agriculture. Available online: http://enrd.ec.europa.eu/. 2012

5. Kretsch, C., van Dijk, J., Schleyer., Public Goods and Ecosystem Services. OpenNESS Synthesis Paper. Available online: http://www.openness-project.eu/. 2016.

6. Ehrlich, P., Ehrlich, A., Holdren, J., Ecoscience: Population, Resources, Environment. W.H. Freeman, San Francisco. 1977.

7. Ehrlich, P., and Mooney, H. A., Extinction, Substitution and Ecosystem Services. BioScience, 33: 248-254. 1983.

8. Power, A., Ecosystem services and agriculture: tradeoffs and synergies. Philosophical Transactions of the Royal Society B: Biological Sciences. 365: 29592971. 2010.

9. European Commission, Sixth Periodic Report on the Social and Economic Situation of Regions in the EU, 1999.

10.http://ec.europa.eu/regional_policy/en/inform ation/maps/regional_competitiveness/\#1

11. Porter, M., The Economic Performance of Regions. Regional Studies, 37(6/7): 549-578. 2003.
12. Martin, R., Thinking about Regional Competitiveness: Critical Issue, Available online:

http://www.intelligenceeastmidlands.org.uk/u ploads/documents/89137/RonMartinpaper1.p df. 2005.

13. Snieska, V., Bruneckiene, J., Measurement of Lithuanian Regions by Regional Competitiveness Index. Inzinerine Ekonomika 61 (1): 45-57, 2009).

14. Staníčková, M., Poledníková, E., The EU Cohesion and Competitiveness in Theory and Practice, Mezinárodní Batova konference prodoktorandy a mladé vědecké pracovníky, Vol.7 (1): 1-28, 2011.

15.Zhu, J., Quantitative Models for Performance Evaluation and Benchmarking: Data Envelopment Analysis with Spreadsheets and DEA Excel Solver, Kluwer Academic Publishers, 2002.

16. Baltagi, H., Econometric analysis of panel data, New York: John Wiley \& Sons Inc. 2008.

17. Garrat, A., Lee, K., Pesaran, M. H., Shin, Y., Global and National Macroeconometrics Modelling. A long Run Structural Approach. Oxford University Press, 2006.

18. Nevima, J., Melecký, L., Regional Competitiveness Evaluation of Visegrad Four Countries through Econometric Panel Data Model, Liberec Economic Forum, Vol.10, (1): 348-361, 2011.

19. Cooper, W. W., Seiford, L. M., Zhu, J., Data Envelopment Analysis: Models and Interpretations, Kluwer Academic Publishers, 2004.

20.Zhu, J., Quantitative Models for Performance Evaluation and Benchmarking: Data Envelopment Analysis with Spreadsheets and DEA Excel Solver, Kluwer Academic Publishers, 2002.

21. Melecký, L., Approaches to Regional Competitiveness Evaluation in the Visegrad Four Countries. Proceedings of the 2nd international conference on Mathematical Models and Methods in Modern Science. p. 184-189. 2011.

22. Millennium Ecosystem Assessment, Ecosystems and Human Well-being: Synthesis. Island Press, Washington, DC, http://www.millenniumassessment.org/docum ents/document.356.aspx.pdf, 2005.

23. Pascual, U., Muradian, R., Brander, L., Gómez-Baggethun, E., Martín-López, B., Verma, M., The economics of valuing ecosystem services and biodiversity, http://www.teebweb.org/, 2010.

24.European Network for Rural Development ONLINE. http://enrd.ec.europa.eu/ 